\title{
An Analysis of Functional Shifting of Word Classes
}

\author{
Changqing Pang \\ Dept. of Basic Courses \\ Shandong University of Science and Technology \\ Jinan, China \\ 13853184438@163.com
}

$$
\text { Di Pang }
$$

Dept. of Social Sciences

University of Tsukuba

Tsukuba, Japan

houteki1997@yahoo.co.jp

\author{
Huimin Liu \\ College of Foreign Languages \\ Shandong University of Science and Technology \\ Qingdao, China \\ 15764255564@163.com
}

\author{
Shanshan Gao \\ College of Foreign Languages \\ Shandong University of Science and Technology \\ Qingdao, China \\ 253064460@qq.com
}

\begin{abstract}
Global integration calls for more efficient language translation techniques, where English-Chinese translation enjoys a higher priority. Practically, the mastery of vocabulary is of great challenge to translators, and this paper focuses on the important translation skill of functional shifting of word classes to flexibly and sufficiently solve vocabulary problem so as to transmit messages exactly and make translation process economical. This paper, on the basis of translation teaching practice, explores the causes of functional shifting of word classes from the perspective of linguistic economics, and summarizes the application laws of functional shifting phenomenon, in order to improve the idiomaticity and accuracy of translation work.
\end{abstract}

Keywords-functional shifting of word class; linguistic economics; translation

\section{INTRODUCTION}

As time goes on, the marketization of translation is becoming more and more clear. According to the 2012 Chinese Language Services Development Report released by Translators Association of China, the linguistic services grew at an average annual rate of 15 percent, equivalent to 2 times of national GDP growth rate. So the cultivation of translation talents has urgent need to strengthen, especially the practical education.

On one hand, in translation teaching, most scholars made studies of vocabulary learning strategies, but few focused on functional shifting of word-class, let alone the reasons, laws or practices. So the researches on functional shifting are almost blank. On the other hand, in actual translation practice, especially the interpreting, the prominent difficulty is to deal with the all-embracing words. Most of these problems can be easily solved by applying the method of functional shifting of word classes. The accuracy of vocabulary use often determines the quality of interpretation, which can be found in the conversion of English native speakers, who are able to always express themselves accurately and efficiently through the functional shifting of simple vocabularies, which embodies the charming of language. After realizing the importance of functional shifting of word classes, the authors analyze the

This is one of the research findings of the project Study on English word class shifting and its translational significances, financially supported by Shanghai Foreign Languages Education Press （2014SD0055A）. practical attributes of functional shifting of word-class from the perspective of linguistic economics, explores the laws of functional shifting phenomenon by a contrast between Chinese and English, and summarizes the significances to translation practice. Thus, the translation ability and translation quality of translation majors and translators will be greatly improved.

\section{The Causes of Functional Shifting of Word Classes}

Linguistic economics is an emerging inter-discipline of economics, linguistics and other related disciplines. It regards language and speech act as ubiquitous social and economic phenomena to be studied mainly by the theories, methods and tools of economics (Zhang, 2009). Linguistic economics takes the theories and methods of economics to examine linguistics, which provides a new path, add new content, and bring new vitality to the study of linguistics.

In English, each word has its own class, which is the grammatical gender of the word. It represents the word's category and the external symbol of word's expressional function. For a word, there are different classes in different situations, which called functional shifting of word-class. From the perspective of linguistic economics, the functional shifting is not a simple lexical problem, but a joint result of language, culture and economy.

Functional shifting of word classes is a basic quality of all languages, which serves the purposes of language efficiency and accuracy, which is very prominent in oral languages. From the aspect of translation, this technique not only helps with easier translation process, but also works for perfecting the target language expression native. Despite the fact that all languages share the same quality, foreign languages learners are not good at using the shifting technique in a foreign language.

From the aspect of economics, functional shifting of word classes is very helpful in making language economical, instead of just adding more words to make language expressing timeconsuming. Functional shifting of word-class can accelerate the speed and efficiency in memorizing words, and greatly improve the effectiveness of communication, which is a 
reflection of great witness of language using method by all human beings.

From the angle of language interpreting, functional shifting of word classes contributes more to the fact that message can be transmitted exactly and accurately, while relieves great burdens from memorizing a larger vocabulary by interpreters.

Nevertheless, the phenomenon of functional shifting of word classes has not been taken theoretically and seriously in the fields of lexicology and translation, which deserves higher attention of researching in order to supply a convenient way to improving translation or interpretation quality.

\section{ThE LAWS OF FUnCTIONAL SHIFTING OF WORD CLASSES}

Generally speaking, among the eight classes of English words, say, nouns, verbs, adjectives, adverbs, pronouns, prepositions, conjunctions, and interjections, functional shifting of word classes mostly occur on nouns, verbs and adjectives.

\section{A. The Functional Shifting of Nouns}

Nouns are words that indicate a person, place, or thing. Nouns are often used as verbs and adjectives, which is called “turn point” by domestic scholar Guo Rui.

\section{1) As verbs}

The nouns, which can be used as verbs, can be roughly divided into the following categories.

a) Nouns of people, such as doctor, nurse, boss, father, mother, baby, etc. e.g.

She nurses her aged mother.

It's not easy to father a child.

Don't baby your child.

b) Nouns of animals, such as dog, pig, snake, monkey, bear, rat, fly, etc. e.g.

The road snakes through the mountains.

Whenever I go, my little brother dogs my footsteps.

Have you ever heard about dogs going ratting?

c) Nouns of parts of human body, such as face, eye, ear, stomach, hand, back, etc. e.g.

A lot of my friends backed my plan.

How can you stomach the violence in the film today?

He gave the child no answer, but eyed him with anger.

d) Nouns of something inanimate, such as house, chair, milk, water, pin, book, etc. e.g.

The apartment houses six persons and a dog.

Pin the bills together so you don't lose them.

His job is to milk a cow.

e) Nouns of time and weather, such as spring, summer, winter, storm, breeze, rain, etc. e.g.

The president sought to spring the hostages.

Madame Lisle breezed into the ballroom.

He stormed angrily at me. f) Some abstract nouns, such as number, anger, time, waste, fun, value, etc. e.g.

We will number them from one to ten.

Time how long it takes me to do two lengths of the pool.

That was the way bourgeois society valued a man.

2) As adjectives

The nouns, which can be used as adjectives, can be divided into two categories.

a) The compound nouns with no space or hyphen between words. The two words are nouns, but the first noun is used as adjective.

A compound word is a noun that is made up of two words. Each compound word acts as a single unit and can be modified by adjectives and other nouns. There are three forms of compound nouns, namely, space compound nouns, like post office, bus stop etc.; hyphened compound nouns, like gettogether, take-in etc.; compact compound nouns without space or hyphen between, like raincoat, bookshop etc. The first noun in the compound is used as an adjective.

The first noun indicates the place where the second noun comes from or where it is found. For example, a Sussex man, a newspaper article, etc.

The first noun indicates the time when the second noun occurs or when it is used. For example, a night light, a day dream, etc.

The first noun indicates what is the second noun made of. For example, an iron bridge, a thriller series, etc.

The first noun provides information about the function, job or role of the second noun. For example, a shoe shop, a police chief, etc.

The first noun is the direct object. For example, adult education, child care, etc.

The first noun is the complement. For example, a women driver, a bench seat, etc.

The second noun is a part of the first noun. For example, the table leg, the car door, etc.

The first noun is a word that represents the weight, height, capacity, length, width, and so on. For example, a tenpound turkey, a five-liter can, etc.

b) The collocation of certain nouns.

All + abstract nouns $=$ very + adjectives E.g.

We are all eagerness to see you.

We were all attention during his lecture.

The students were all ears when they were listening to the teacher's lecture.

Of + noun $=$ adjective E.g.

He is a man of courage.

Environment protection is of great importance. 
The earth is (of) the shape of a pear.

Her dress is (of) the color of grass.

Noun + enough $=$ adjectives E.g.

We were fools enough to believe her.

This is invitation enough.

He was joking, and I was fool enough to believe it.

Abstract nouns + itself $=$ very + adjective E.g.

Mr. Smith is prudence itself.

In money matters she was scrupulousness itself.

To his superiors, he is humanity itself.

\section{B. The Functional Shifting of Verbs}

Verbs are used to indicate actions, conditions, or states of people or things. It is tendency that more and more verbs are used as nouns as English language develops. Generally speaking, verbs can be shifted into nouns under the following three circumstances, namely, nouns indicate conditions or states of verbs; nouns indicate names of people or things; and nouns indicate names of something that have nothing to do with the original verbs.

1) Nouns indicate the conditions or states of verbs, such as, feel, act, divorce, ban, help, etc. E.g.

I like the feel of silk.

He tried to fence off the consequences of his foolish act.

There should be a ban on tobacco advertising.

2) Nouns indicate names of people or things, such as, feed, design, exhibit, lock, light, display, etc. E.g.

They draw up the design for the house in a week.

He picked each lock deftly, and rifled the drawer papers.

The first exhibit was a knife, which the prosecution

claimed was the murder weapon.

3) Nouns indicate names of something that have nothing to do with the original verbs, such as fall, share, hit, die, etc. E.g.

I know the film will make a hit.

Employees wanted more shares than were available.

Victoria Falls has had above average levels of rainfall.

\section{The Functional Shifting of Adjectives}

Adjectives are describing words, which are added to nouns to describe category, color, quantity, quality etc.. Adjectives are generally used to modify nouns. It is very common to find that adjectives are frequently used as nouns and verbs.

\section{1) As Nouns}

The adjectives, which can be used as nouns, can be divided into two categories.

a) The + adjectives $=$ nouns E.g.

The structure of "the + adjectives" represents a kind of people, such as, the rich, the dead, the disabled, the deaf, the blind, etc.
These seats are for the disabled.

This is a school for the deaf and the blind.

Wealth has to be redistributed from the rich to the poor.

The structure of "the + adjectives" represents some abstract things, such as, the good, the bad, the beautiful, the ugly, etc. E.g.

Their aim was to discover the good, the beautiful and the true.

It is highly important to distinguish between the false and the true.

In countries' names, “the + adjectives ”(ended with -ch, -sh, -ese) represents the citizens of that country, such as, the Chinese, the French, etc. E.g.:

The French like to eat well.

The Chinese make a point of their personal honor.

b) Some adjectives can be shifted into into nouns when the names of same things are similar to the quality of them, such as chemical, mineral, numeral, periodical, radical, etc. E.g.

The mineral is weakly magnetic.

They have already put out a new periodical.

Scientists tried out thousands of chemicals before

They found the right one.

\section{2) As Verbs}

In communication, adjectives can be used to state the process or result of realizing some attributes rather than describing the characters of things. Therefore, some adjectives are used as verbs to indicate the action. E.g.

The man-made satellite rounds the earth every day.

Her medical course was completed ahead of time.

You have to content yourself with what you have.

\section{ThE SignificANCE OF FUnCTIONAL SHIFTING OF WORD CLASSES}

In actual translation practice, especially interpreting, the mastery of vocabulary plays an important role for translators, and it is also extremely challenging. In order to master vocabulary well, the most important is to use these words flexibly. Functional shifting of word classes is a vital key to flexible use of word classes and vocabulary so as to make translation process easier and more accurate.

For one thing, the larger vocabulary one acquires, the more effectively he can perform in the communication activities. However, it is impossible for a translator to master all the words. Practically speaking, by shifting corresponding word classes, clear and exact massages can be conveyed and some difficulties in the process of translating or interpreting can be easily solved. Therefore, in the case of insufficient vocabulary, the skill of word class shifting makes a sufficient remedy. For another, accuracy of vocabulary use determines the quality of interpretation. It is very clear that English native speakers are always found to express themselves by using simple words instead of many complicated ones, which is realized by applying the skill of world class shifting. In interpreting 
practice, this method is very important, since it greatly improves the idiomaticity and accuracy of English language, raveling the charming of the languages at the same time.

\section{CONCLUSION}

In conclusion, the generation of functional word class shifting is of great significance to understanding the language of English, to translating or interpreting Chinese into English. To the above end, specific laws guiding word class shifting should be given more room and attention for further research, which will make a greater difference for translators, especially for interpreters, where the skill serves as an effective tool to improving language translation accuracy and efficiency, and remedying the problem of inadequate amount of vocabulary.
More research effort has to be engaged in the phenomenon of word class shifting for the purposes of English language understanding and translation practice.

\section{REFERENCES}

[1] D. A. Wilkins. Linguistics in Language Teaching[M]. The MIT Press. 1972.

[2] Li Zhixiao. Discussions on the Changes of Word-class[J]. Qilu Journal, 1994(4): 45-47.

[3] Su Baorong. The Study of Functional Shifting and Functional Meaning of Words[J]. Linguistic Researches, 2003(04): 10-14.

[4] Zhang Weiguo. The Three Dimensions of Linguistic Economics[N]. Guangming Daily, 2009. 